\title{
A UNIVERSIDADE PORTUGUESA: ONTEM E HOJE - DA SUA ORIGEM AO SÉCULO XVIII
}

Dora Resende Alves ${ }^{1}$

\section{Resumo}

Ontem e hoje, a Universidade apresenta-se como centro de reflexão e também centro de atenção dos poderes públicos, ontem, o rei, hoje, os ministérios correspondentes e as comissões especializadas. A Universidade Portuguesa representa uma instituição, de entre as suas congéneres europeias, com especificidades ligadas à evolução política do Reino, da sua origem ao século XVIII. É oportuno lembrar esta origem específica, mantendose a única instituição de ensino superior do país até ao século XVI, num momento presente em que a condição da Universidade e dos estudos superiores voltam a ser tão falados e estudados.

Palavras-chave: Universidade, Direito, Estatutos.

\section{INTRODUÇÃO}

As características únicas do surgimento da universidade portuguesa servem de mote à ponderação do papel da universidade na história europeia, desde a sua criação até hoje.

Deveras, o modo de criação e desenvolvimento da instituição em cada país pode condicionar o entendimento que hoje, lhe é dado.

$\mathrm{Na}$ investigação proposta, pretende demonstrar-se que, ontem e hoje, a Universidade apresenta-se como centro de reflexão e também centro de atenção dos poderes públicos, ontem, o rei, hoje, os ministérios correspondentes e as comissões especializadas. Por outras palavras, o presente trabalho tem por finalidade realizar estudo da evolução dos estudos superiores em Portugal, para debater os elementos gerais das suas fórmulas e ralação com o poder.

Desse modo, no primeiro momento, é realizado um apanhado geral a respeito do entendimento da universidade como centro de conhecimento no modelo europeu.

Em seguida, são apresentadas as características próprias do aparecimento de um Estudo Geral português.

Por fim, verificada a relação com o poder do rei através da criação de Estatutos para a Universidade.

\footnotetext{
${ }^{1}$ Doutora em Direito. Professora Auxiliar e Investigadora da Universidade Portucalense Infante D. Henrique, Porto, Portugal. Email:dra@upt.pt
} 
Portanto, o critério metodológico utilizado no trabalho apresenta características de análise histórica: etapa de conhecimento, em que são expostos conceitos de que partimos; etapa de compreensão, que procura expor a evolução histórica da universidade portuguesa com detalhe e contextualização; etapa de comparação, onde todo conteúdo já apresentado é submetido a confronto, alcançando os objectivos propostos pelo trabalho de conhecimento da realidade histórica para entender a posição da universidade nos dias de hoje.

A conclusão busca unir os pontos apresentados para reflectir sobre a posição e problemas da universidade nos dias de hoje.

\section{A UNIVERSIDADE}

$\mathrm{O}$ conceito de universidade surge no século XV por referência uma instituição de ensino e pesquisa constituída por um conjunto de faculdades e escolas destinadas a promover a formação profissional e científica de pessoal de nível superior, e a realizar a pesquisa teórica e prática nas principais áreas do saber humanístico, tecnológico e artístico e a divulgação dos seus resultados à comunidade científica mais ampla. O termo aplica-se ainda ao conjunto das edificações e instalações físicas nas quais funciona essa instituição e mesmo ao pessoal docente, discente e administrativo dessa instituição².

As universidades surgem com o nascimento de núcleos urbanos na orla do Mediterrâneo e o aparecimento das Cruzadas, como corporações livres, de mestres e alunos, que tinham como principal objectivo aprofundar e difundir o saber entre os seus membros3. "A universidade como instituição que elabora e mantém vivos os conhecimentos de ordem teorética é uma criação europeia, surgida na Idade Média e designada studium generale, comunidade de mestres e estudantes (universitas magistrorum et scholarium), administrando-se a si mesma e tendo por finalidade o estudo do conjunto de conhecimentos que não relevam apenas da simples habilidade manual e contribuem para o mais elevado desenvolvimento da pessoa humana. Nas suas linhas mestras a estrutura da Universidade foi-se mantendo até finais do século XVIII. Com o dealbar da centúria seguinte vão as universidades abandonando a autonomia que mantinham face ao poder civil, iniciando uma etapa de mais estreita vinculação a esse poder." ${ }^{4}$

Durante toda a Antiguidade, o acesso à cultura tinha sido exclusivo para um reduzido número de privilegiados. Na Idade Antiga, houve escolas de ensino superior com o culto das artes pelas artes, sem um rumo

\footnotetext{
${ }^{2}$ Dicionário Houaiss da Língua Portuguesa. Lisboa: Temas e Debates, 2003, p. 3635.

${ }^{3}$ ALVES, Manuel Valente. História da Medicina em Portugal. 2014, p. 49.

${ }^{4}$ Polis.Enciclopédia Verbo da Sociedade e do Estado. Vol 5, p. 1424.
} 
definido ou objectivo social a preencher pelas escolas particulares e oficiais da Antiguidade grega e romana ${ }^{5}$.

A Igreja, ao proclamar a igualdade de todos os homens perante Deus, permitiu, nas escolas eclesiásticas desde o começo da Idade Média, o ensino gratuito de todos os que pretendiam dedicar-se à carreira eclesiástica. $\mathrm{Na}$ Alta Idade Média, o estudo das artes e das letras passa a ter o objectivo bem determinado de servir a Igreja, através duma melhor preparação para o exercício das funções eclesiásticas e como sentido social. A comunidade que a universidade medieval serve é a comunidade cristã ${ }^{6}$.

O ensino elementar e médio estava espalhado por toda a parte onde houvesse uma catedral, um mosteiro ou uma simples igreja paroquial. Já o ensino superior estava concentrado em meia dúzias de lugares, ao longo da Europa?

Nos primeiros séculos da era cristã houve escolas superiores que prolongaram a sua acção, mas a Universidade só surgiu em meados do século XII e a palavra começou por designar a "comunidade" de mestres e alunos que se reuniam para a transmissão do saber ${ }^{8}$. Ainda assim, a primeira é a Universidade de Bolonha, fundada na Itália em 1088 com o ensino de Direito. Depois a Universidade de Paris em 1150, destinada a completar o ensino da Teologia ministrado na Catedral de Notre-Dame. Em 1181, a de Montpellier com o ensino da Medicina (como escola e transformada em 1298 por bula papal). A Universidade de Salamanca surge em 1218. Entre outras, a Universidade de Toulouse em 1299 e a Universidade de Valladolid em 1346 9.

A universidade é uma criação sublime do espírito medieval e muitas das universidades criadas na Idade Média mantêm-se até aos nossos dias. A Universidade é uma nova instituição que nasce e se expande desde o início da Baixa Idade Média. Nestas visa-se formar o estudante para este poder valer por si mesmo na aplicação e aprofundamento dos conhecimentos que lhe são transmitidos ${ }^{10}$. Porém, as suas origens são diversas ${ }^{11}$.

As primeiras universidades formaram-se espontaneamente, através dum característico processo de crescimento e corporatização duma escola ou escolas locais, já existentes - por formação consuetudinária ou ex consuetudine. As Universidades de Oxford (com registos desde 1096) no Reino Unido, Bolonha, Paris, Montpellier e Orléans em França.

Outras vezes, o processo de formação de novas universidades resultava de uma separação ou secessão ex secessione, constituindo um desmembramento de uma outra universidade já existente. São universidades

\footnotetext{
${ }^{5}$ CRUZ, Guilherme Braga da. O essencial sobre A História da Universidade. 2008, pp. 63 e 55.

${ }^{6}$ Idem, p. 64.

${ }^{7}$ Idem, pp. 63 e 56.

${ }^{8}$ SERRÃO, Joaquim Veríssimo. História das Universidades.1983, p. 11.

${ }^{9}$ ALVES, Manuel Valente. História da Medicina em Portugal. 2014, p. 49.

${ }^{10}$ SOARES, Fernando. Ensaio para a História .... 2009, p.84.

${ }^{11}$ CRUZ, Guilherme Braga da. O essencial sobre A História da Universidade. 2008, pp. 5 e 8 a 15.
} 
fundadas, criadas ex novo em data certa As Universidades de: Cambridge (em 1209 ${ }^{12}$ ) no Reino Unido, Pádua (em 1222 $\left.{ }^{13}\right)$, na Itália.

Outras ainda aparecem ex privilegio, surgem por efeito da deliberação de um soberano mas carecem de confirmação pontifícia. Só o Papa pode reconhecer a validade universal aos graus académicos por elas outorgados. A Universidade de Palência em Espanha, fundada pelo rei Afonso VIII de Castela em 1212, a de Nápoles em Itália, fundada pelo imperador Frederico II em 1224 ou a de Toulouse em França criada pelo conde local em 1229.

Ainda nos surgem universidades criadas directamente pelo Papa como a Universidade de Freiburg (fundada por Bula papal de $1457^{14}$ ) na Alemanha. Neste país, surge anterior uma das mais antigas da Europa, a de Heidelberg em 1386, situada no länder alemão onde hoje se encontra a região europeia com a mais alta concentração de instituições de ensino superior de todo o continente.

Em regra, na Idade Média, para designar as Universidades, utiliza-se a expressão Studium generale. Por seu turno, para aludir a centros de docência de categoria inferior ou mais restrita, usa-se Studium particulare. Só desde meados do século XIII se começa a empregar a terminologia universitas, a qual se generaliza no século $X V^{15}$.

\section{A CRIAÇÃO DA UNIVERSIDADE PORTUGUESA}

Desde os primeiros tempos do reino existiram escolas episcopais (fundadas pelos bispos) e monacais, por regra para instrução do clero, admitindo eventualmente a frequência de alguns leigos. A Universidade portuguesa é uma criação inteiramente nova, fundada ex novo pelo rei D. Dinis. ${ }^{16}$

Em 12 de Novembro de 1288, no reinado de D. Dinis (1279-1325), ${ }^{17}$ é dirigida uma petição ao Papa Nicolau IV, assinada por membros do Clero em que se solicita a autorização (confirmação) papal para o estabelecimento de um Estudo Geral em Lisboa e (ser o Clero a suportar as despesas) a autorização para custear as despesas (salários dos mestres e doutores) com os rendimentos do clero (rendas dos mosteiros e igrejas).

\footnotetext{
${ }^{12}$ Nascida por iniciativa de um grupo de professores da de Oxford, em conflito com as autoridades locais e tornando-se grande rival.

${ }^{13}$ Por secessão de um grupo de estudantes da de Bolonha, revoltados com o ambiente restritivo das liberdades académicas, que criaram uma universitas scholarium, corporação dotada de leis e estatutos próprios, que se detinava ao ensino do direito. Em 1399 é criada uma segunda universidade de artes, para o ensino de filosofia, medicina, retórica e gramática. ALVES, Manuel Valente. História da Medicina em Portugal. 2014, p. 50.

${ }^{14}$ RODRIGUES, Eduardo R. Lopes. Política de concorrência focada na competitividade e na confiança dos cidadãos in Revista do Ministério Público. Ano 29, n. ${ }^{0}$ 113, Jan-Mar 2008, p. 25.

${ }^{15}$ SOARES, Fernando. Ensaio para a História ....2009, p.84.

${ }^{16}$ CRUZ, Guilherme Braga da. O essencial sobre A História da Universidade. 2008, p. 15.

${ }^{17}$ CUNHA, Joaquim Silva. História das Instituições. Aulas Teóricas. Vol. I, 2. a ed., p. 250 e ALMEIDA, Carlos Marques de. História das Instituições. Aulas Práticas. Vol. I. Texto a p. 525.
} 
O pedido fundava-se em 2 razões: estimular a ciência e a religião e criar um centro de cultura como estímulo, não afastando os de menores recursos por terem de se deslocar ao estrangeiro e representava mais prestígio para o Reino.

As universidades da Europa eram muitas vezes inacessíveis àqueles que desejavam procurar os estudos superiores, pelas elevadas somas que era necessário despender para aí se deslocarem e para se sustentarem durante o largo período de duração dos estudos. ${ }^{18}$

Foi o Clero a fazer o pedido e era de facto o principal interessado na fundação do Estudo Geral. D. Dinis atravessava um período de certas discordâncias com Roma, não era oportuno dirigir-se ele próprio como autor do plano.

No entanto, a bula só veio 2 anos mais tarde. ${ }^{19}$

Entretanto, em 1 de Março de $1290{ }^{20}$ é concedida uma Carta de Privilégios por D. Dinis à Universidade ${ }^{21}$ para o estudo de todos os que quisessem frequentá-la, o que pressupõe uma fundação anterior e a situa entre 1288 e 1290, tornando a universidade portuguesa essencialmente uma fundação régia.

Talvez o Papa retardasse a aprovação e talvez esta Carta tivesse apressado essa aprovação.

Em 9 de Agosto de $1290^{22}$ uma Bula de Nicolau IV vem autorizar as despesas (o pagamento dos salários e concedendo privilégios aos docentes e escolares), confirmando o ensino dos cursos de ${ }^{23}$ :
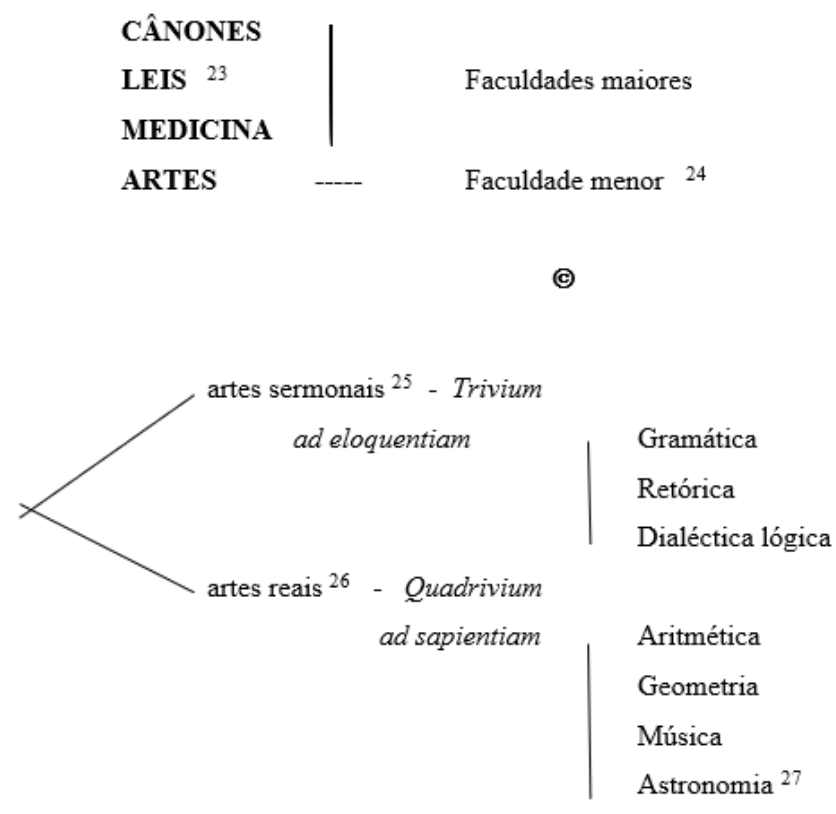

\footnotetext{
${ }^{18}$ CRUZ, Guilherme Braga da. O essencial sobre A História da Universidade. 2008, p. 64.

${ }^{19}$ SERRÃO, Joaquim Veríssimo. História das Universidades.1983, p. 58.

${ }^{20}$ ALMEIDA, Carlos Marques de. História das Instituições. Aulas Práticas. Vol. I. Texto a p. 533.

${ }^{21}$ Terminologia que começa a ser utilizada a partir desta época, embora a designação Estudo Geral se mantivesse até ao século XVI.

${ }^{22}$ ALMEIDA, Carlos Marques de. História das Instituições. Aulas Práticas. Vol. I. Texto a p. 537.
} 
Nesta época, as disciplinas que a universidade ensina são apenas as que possuem valor universal, o que equivale a dizer que o ensino universitário é igual em toda a parte. ${ }^{24}$

$\mathrm{Na}$ base da hierarquização científica das disciplinas universitárias estavam as disciplinas preparatórias que constituíam o trivium e o quatrivium, que recebiam, no seu conjunto a denominação de artes liberais. A elas se seguiam as ciências propriamente ditas, objecto das várias Faculdades num síntese destinada a conhecer os problemas do homem na ordem dos seres criados - objecto da filosofia e da medicina, os problemas do homem nas suas relações com os outros homens - objecto do direito, e os problemas do homem e da natureza nas suas relações com Deus - objecto da teologia. ${ }^{25}$

O grau de licenciado (licença para ensinar) era dado pelo Bispo de Lisboa. Conferia o ius ubique docendi - o direito de ensinar em qualquer parte, o que é a expressão completa do carácter ecuménico do ensino universitário medieval. ${ }^{26}$

Não dava ainda autorização para Teologia (Sacra pagina) ${ }^{27}$, o que manteve a ida para o estrangeiro (Salamanca, Toulouse, Paris, Oxford) de muitos escolares teólogos. ${ }^{28}$

De Orvieto ${ }^{29}$, dirigida à "Universidade dos mestres e escolares de Lisboa".

A Universidade medieval gozou de uma completa liberdade de movimentos. Quando os incidentes de ordem social entre estudantes e burgueses impediam o regular funcionamento dos cursos, a Universidade levantava arrais e ia instalar-se noutro lugar e por vezes regressava mais tarde. ${ }^{30}$

Durante o primeiro século de existência (90 anos), a universidade portuguesa sofreu diversas modificações e 5 transferências, caso único de itinerância nas universidades medievais europeias. ${ }^{31}$

Neste tempo não havia edifícios escolares e o próprio material didáctico se resumia a uns quantos livros que os próprios estudantes copiavam para uso próprio. As aulas davam-se nos claustros das sés ou mosteiros ou em modestas casas de aluguer. ${ }^{32}$

Assim se podem identificar os seguintes marcos:

\footnotetext{
${ }^{23}$ CUNHA, Joaquim Silva. História das Instituições. Aulas Teóricas. Vol. I, 2. a ed., p. 251, ver nota de roda-pé.

${ }^{24}$ CRUZ, Guilherme Braga da. O essencial sobre A História da Universidade. 2008, p. 57.

${ }^{25}$ Idem, p. 39.

${ }^{26}$ Idem, pp. 14 e 58.

${ }^{27}$ Só no século XV Teologia deixou de ser monopólio da Ordem dominicana. A Ordem de S. Francisco obteve autorização para reger Teologia em 1328, mas só em 1400 figurou no elenco das cadeiras. Cânones - estudo da disciplina eclesiástica e regras sobre matérias de fé.

₹ Teologia - estudo da existência de Deus (T. Dogmática ou revelada - estudo dos dogmas da fé, baseado nos textos sagrados e na autoridade da Igreja).

${ }^{28}$ SERRÃO, Joaquim Veríssimo. História das Universidades.1983, p. 58.

${ }^{29}$ Cidade medieval perto de Roma.

${ }^{30}$ CRUZ, Guilherme Braga da. O essencial sobre A História da Universidade. 2008, p. 12.

${ }^{31}$ SERRÃO, Joaquim Veríssimo. História das Universidades.1983, p. 59.

${ }^{32}$ CRUZ, Guilherme Braga da. O essencial sobre A História da Universidade. 2008, p. 11.
} 
1. 1290? - D. Dinis estabeleceu o Estudo Geral no Bairro de Alfama em Lisboa, chamado Campo da Pedreira, em edifício mais tarde conhecido por "Moeda Velha". ${ }^{33}$

2. até 1308 manteve-se em Lisboa.

3. 1308 - D. Dinis mudou-a para Coimbra, terra mais propícia ao labor do espírito e passa a chamar-se Universidade.

4. 15 de Fevereiro de 1309 - Carta de protecção de D. Dinis aos estudantes da Universidade de Coimbra, por razões de centralidade e sossego. ${ }^{34}$

5. 1338 - D. Afonso IV transfere-a para Lisboa, para atrair professores e fomentar a vida escolar.

6. 1354 - D. Afonso IV decide novamente mudá-la para Coimbra, para evitar os conflitos entre estudantes e a população da capital, considerando que Coimbra possuía melhores condições.

7. 1357 - Alvará de D. Pedro sobre os livros de estudo ${ }^{35}$ que distinguia: as Faculdades maiores (Leis, Cânones, Medicina) cujo ensino particular proibia e a Faculdade menor (Artes), em que era permitido.

8. 3 de Junho de 1377 - D. Fernando arranja casas no Bairro de Alfama e por carta régia muda o Estudo Geral para Lisboa.

9. 1431 - Carta de doação do Infante D. Henrique à Universidade de Lisboa.

D. João I cria o cargo de protector do Estudo Geral, ocupado por: ${ }^{36}$

a) Chanceler Dr. João das Regras até 1404

b) Dr. Gil Martins

c) Infante D. Henrique de 1418 a 1460.

Visto que a universidade andava sempre por casas alheias e de aluguer, como coisa desabrigada e desalojada. Entende que deve ter morada e casa próprias, que comprou. ${ }^{37}$.

Indica onde se ensinam a Gramática (na casa de fora por causa do ruído)

Lógica

Retórica

Aritmética

Música

Geometria

\footnotetext{
${ }^{33}$ ALMEIDA, Carlos Marques de. História das Instituições. Aulas Práticas. Vol. I. p. 537.

${ }^{34}$ Idem, p. 541.

${ }^{35}$ Idem. Texto a p. 545.

${ }^{36}$ CUNHA, Joaquim Silva. História das Instituições. Aulas Teóricas. Vol. I, 2. a ed., p. 334.

${ }^{37}$ ALMEIDA, Carlos Marques de. História das Instituições. Aulas Práticas. Vol. I. Texto a p. 553.
} 
Astrologia ${ }^{38}$

E para cada local que se pintem figuras importantes em cada área:

\begin{tabular}{|c|c|c|c|}
\hline Medicina & - & Galeno & (médico grego do século II a.C.) \\
\hline Cânones & - & um Papa & \\
\hline Artes & - & Aristóteles & (filósofo grego, 384-322 a.C.) \\
\hline Leis & - & um Imperado & $\left(\right.$ romano ?). ${ }^{39}$ \\
\hline
\end{tabular}

1537 - D. João III muda-a definitivamente para Coimbra, mantendo-se a única universidade portuguesa sem interrupções de ensino até $1911 .^{40}$

A Universidade interfere na estrutura social e vida política, apoiou a causa do Mestre d'Avis e durante o reinado de D. João I (1385-1433) e com a Ínclita Geração (Camões) o papel da Universidade foi muito relevante na preparação de uma nova classe de juristas e letrados depois aos poucos integrados na administração pública ${ }^{41}{ }^{42}$

\section{OS PRIMEIROS ESTATUTOS DA UNIVERSIDADE PORTUGUESA ${ }^{43}$}

As universidades dos séculos XII e XIII apresentam uma importante característica comum: gozam de completa autonomia institucional que se traduz numa independência absoluta, para efeitos jurídicos e administrativos. A universidade é dotada de personalidade própria, governa-se a si própria, organiza o seu ensino. Os reis e os papas interferem na vida da universidade para the dar a existência e depois para a cumular de privilégios ou regalias. Embora seja verdade que ela está colocada ao serviço da comunidade cristã, da Igreja de Roma como aceitação de um ideal ou norma de vida. ${ }^{44}$

A publicação do livro das Siete Partidas de Afonso X, o Sábio (1256-1263) fez surgir a primeira legislação

\footnotetext{
${ }^{38}$ ALMEIDA, Carlos Marques de. História das Instituições. Aulas Práticas. Vol. I. p. 555.

${ }^{39}$ Ibidem, p. 556.

${ }^{40}$ Em virtude destas mudanças, as Universidades de Coimbra e de Lisboa de hoje ainda, cada uma delas, reclamam ser a legítima herdeira da primeira fundação.

Ver em Exposição enviada pelo Senado Universitário de Coimbra ao Senado Universitário de Lisboa com a moção aprovada por unanimidade em sessão de 27 de Fevereiro de 1960, Edição da Associação dos Antigos Estudantes de Coimbra, e em Documentos da Universidade de Lisboa - sobre a exposição da Universidade de Coimbra de Fevereiro de 1960, ambos policopiados.

${ }^{41}$ Relacionando-se o tema com: a ascensão social dos letrados (elementos do povo que através dos estudos acedem a cargos até aí ocupados por elementos de linhagem); a complexidade crescente dos negócios públicos; as alterações no reinado de D. João I, como contrapartida aos apoios recebidos.

${ }^{42}$ CUNHA, Joaquim Silva. História das Instituições. Aulas Teóricas. Vol. II, p. 502.

${ }^{43}$ Hoje, os Estatutos da Universidade Portucalense Infante D. Henrique, no Anúncio n. ${ }^{\circ} 6952 / 2009$, nos termos do n. 3 do artigo 142. ${ }^{\circ}$ da Lei n. ${ }^{\circ}$ 62/2007, de 10 de Setembro, publicados no Diário da República, 2. a série, n. ${ }^{\circ} 179$ de 15 de Setembro de 2009, pp. 37741 a 37747. Os anteriores publicados pelo Aviso n. ${ }^{\circ} 111 / 2006$ no Diário da República de 16 de Agosto de 2006 (www.upt.pt). ${ }^{44}$ CRUZ, Guilherme Braga da. O essencial sobre A História da Universidade. 2008, pp. 15 a 17.
} 
oficial para o governo universitário. ${ }^{45}$

Com o fortalecimento do poder real, desde o século XIII em diante, perderá a sua independência administrativa e depois doutrinal. As novas universidades que então surgem apresentam ab initio uma subordinação ao poder real. ${ }^{46}$

Estatutos Manuelinos ${ }^{47}$

O Renascimento provoca um período cultural brilhante.

No início do século XVI, a interferência régia na Universidade acentua-se.

É D. Manuel (1495-1521) a estabelecer nomeações e contratos de professores, concedendo uns Estatutos à Universidade, nos finais do século XV (1495?).

Confirma 3 cátedras remuneradas de Cânones e 3 de Leis e acrescenta mais 1 cátedra de Cânones.

D. João III (1521-1557) limita-se a interferir na vida administrativa da universidade. ${ }^{48}$

Não concedeu novos estatutos à Universidade. Limitou-se a fazer algumas alterações nos Estatutos Manuelinos, em 1537, ordenando que continuassem em vigor. ${ }^{49} \mathrm{~A}$ Inquisição afecta o seu funcionamento e os Jesuítas tomam a sua direcção. ${ }^{50}$

Em 1544 foi pedida (determinada) uma reforma e promulgada uma lei para reger a Universidade. ${ }^{51}$

Estatutos Filipinos

A reforma surgiu com os mais tarde chamados Estatutos Velhos ${ }^{52}$, de 1597 / 98, no reinado de Filipe II de Espanha, I de Portugal (1580-1598)

(revistos, acrescentados e confirmados por Filipe III, II de Portugal (1598-1621), em 1612)

o ensino repartia-se por duas Faculdades:

Cânones ( 2 cátedras de Decretais, uma de Sexto, outra de Clementinas e 2 catedrilhas de Decretais) e

Leis (uma cátedra de Esforçado, outra de Digesto Novo, outra de Digesto Velho e uma quarta de estudo dos 3 livros do Código; e ainda 2 catedrilhas do Código e 2 de Institutas).

O ensino era em latim, os cursos de 6 anos e o método utilizado consistia na leitura e comentário sumário pelos professores.

Foi criada uma Universidade em Évora, em 1/Novembro 1559, autorizada pela Bula Cum A Nobis de

\footnotetext{
${ }^{45}$ SERRÃO, Joaquim Veríssimo. História das Universidades.1983, p. 53.

${ }^{46}$ CRUZ, Guilherme Braga da. O essencial sobre A História da Universidade. 2008, p. 18.

${ }^{47}$ CUNHA, Joaquim Silva. História das Instituições. Aulas Teóricas. Vol. II, p. 633 na 1. a ed. e p. 428 na 2. a ed..

${ }^{48}$ CRUZ, Guilherme Braga da. O essencial sobre A História da Universidade. 2008, p. 30.

${ }^{49}$ SERRÃO, Joaquim Veríssimo. História das Universidades.1983, p. 109.

${ }^{50}$ CUNHA, Joaquim Silva. História das Instituições. Aulas Teóricas. Vol. II, p. 635 na 1.a ed. e p. 525 na 2. a ed., ver nota de roda-pé.

${ }^{51}$ SERRÃO, Joaquim Veríssimo. História das Universidades. 1983, p. 109.

${ }^{52}$ Excerto em CURA, António Alberto Vieira Cura. Direito Romano e História do Direito Português (Casos Práticos Resolvidos e Textos), 2. edição. Coimbra Editora, 2009, pp. 329 a 335.
} 
Paulo IV, de 15 de Abril de 1559, no reinado do Cardeal D. Henrique (1578-1580), 53 com ensino de Artes, Teologia e Direito Canónico,

entregue a jurisdição à Companhia de Jesus, com actividade durante 2 séculos e regalias especiais concedidas pelo Papa. ${ }^{54}$

D. João IV (1640-1656) reconfirma os Estatutos Filipinos em 1653. ${ }^{55}$

O que se segue na vida institucional da universidade é a reforma do século XVIII, levada a cabo pelo despotismo esclarecido, sob inspiração do mvimento iluminista. ${ }^{56}$

Em 3 de Setembro de 1759, no reinado de D. José (1750-1777), dá-se a expulsão dos Jesuítas do Reino com o consequente encerramento das suas escolas e colégios, por Sebastião José de Carvalho e Melo, primeiro Marquês de Pombal e seu ministro ${ }^{57.58}$

Consequentemente encerrou a Universidade de Évora. ${ }^{59}$

A política contra a Companhia de Jesus culminou em 1767 com a publicação da Deducção Chronologica e Analytica, obra que pretendia resumir e provar as desordens causadas pelos Jesuítas no Reino e domínios ultramarinos. Sem nome de autor, foi atribuída ao desembargador José Seabra da Silva, mas hoje não oferece dúvidas que o seu autor foi o Marquês de Pombal. ${ }^{60}$

Por Carta de lei de 23 de dezembro ${ }^{61}$ de 1770 é criada a Junta da Providência Literária, com a tarefa (incumbência) de estudar deficiências existentes no ensino universitário e de sugerir as reformas julgadas necessárias.

Em 1771, a Junta apresenta um relatório ${ }^{62}$ : o Compêndio Histórico do estado da Universidade de Coimbra ao tempo da invasão dos denominados Jesuítas, publicado em 1772, no qual se atribuem aos Jesuítas todas as causas da decadência da Universidade e apontam-se novos caminhos de reforma.

Em consequência procede-se à Reforma da Universidade de Coimbra ${ }^{63}$ decretada por Pombal, sob influência do Verdadeiro Método de Estudar do Padre Luís António Verney, em 1747, que faz uma violenta

\footnotetext{
${ }^{53}$ CUNHA, Joaquim Silva. História das Instituições. Aulas Teóricas. Vol. II, p. 636 na 1.a ed. e p. 525 na 2. a ed..

${ }^{54}$ SERRÃO, Joaquim Veríssimo. História das Universidades.1983, p. 111.

${ }^{55}$ CUNHA, Joaquim Silva. História das Instituições. Aulas Teóricas. Vol. II, p. 763.

${ }^{56}$ CRUZ, Guilherme Braga da. O essencial sobre A História da Universidade. 2008, p. 28.

${ }^{57}$ Veja-se a série televisiva "O Julgamento dos Távoras", passada em início de 2003.

${ }^{58}$ CUNHA, Joaquim Silva. História das Instituições. Aulas Teóricas. Vol. II, p. 917.

${ }^{59}$ SERRÃO, Joaquim Veríssimo. História de Portugal. p. 260.

${ }^{60}$ CUNHA, Joaquim Silva. História das Instituições. Aulas Teóricas. Vol. II, 2.a ed., p. 937 e 654 e SERRÃO, Joaquim Veríssimo. História de Portugal. p. 265.

${ }^{61} 21 /$ Set./1770 ??? 23/Dez./1768 ???

${ }^{62}$ CUNHA, Joaquim Silva. História das Instituições. Aulas Teóricas. Ver Capítulo I, Vol. I, p. 43.

${ }^{63}$ CUNHA, Joaquim Silva. História das Instituições. Aulas Teóricas. Vol. II, 2.a ed., p. 841 e 584.
} 
crítica aos métodos usados nos diversos ramos de ensino. ${ }^{64}$

A chamada Reforma Pombalina da Universidade insere-se num processo histórico em que o Despotismo Iluminado exerceu um papel determinante. ${ }^{65}$

Esta reforma do ensino foi imposta despoticamente pelo Estado, segundo o pensamento político da época. O Estado chamou a si a tarefa de realizar a reforma do ensino segundo os ideais do iluminismo reformista. O Estado indica à universidade as disciplinas que deve ensinar e que orientação geral deve seguir no seu ensino, organizando para cada cadeira, um programa com as matérias que devem ser ensinadas e não. A universidade acaba sendo um organismo estadual, exclusivamente ao serviço dos ideais ético-políticos do próprio Estado. ${ }^{66}$

Estatutos Pombalinos ${ }^{67}$

Os Estatutos Pombalinos ou Estatutos Novos, prontos em $1772{ }^{68}$, trazem alterações na estrutura do ensino, em que diminui a importância dada ao Direito Romano e aumenta a importância do estudo da História e do Direito Pátrio:

- criam 2 novas faculdades: Matemática

Filosofia Natural

- Faculdade de Leis

$$
\begin{aligned}
& 8 \text { disciplinas }{ }^{69}: \\
& \cdot 1 \text { subsidiária } \\
& \text { História Civil dos Povos e do } \\
& \underline{\text { Direito Romano }}{ }^{70} \text { e Português } \\
& .2 \text { elementares } \\
& .3 \text { sintéticas } \\
& 2 \text { de Direito Romano } \\
& 1 \text { de Direito Pátrio } \\
& .2 \text { analíticas } \\
& 2 \text { de Direito Romano e Pátrio }
\end{aligned}
$$

Faculdade de Cânones ${ }^{71} 7$ disciplinas

\footnotetext{
${ }^{64}$ CUNHA, Joaquim Silva. História das Instituições. Aulas Teóricas. Vol. I, 2.a ed., p. 43.

${ }^{65}$ SERRÃO, Joaquim Veríssimo. História das Universidades.1983, p. 143.

${ }^{66}$ CRUZ, Guilherme Braga da. O essencial sobre A História da Universidade. 2008, p. 29.

${ }^{67}$ CUNHA, Joaquim Silva. História das Instituições. Aulas Teóricas. Vol. II, 2.a ed., p. 938 e 654 e Vol. I, p. 44.

${ }^{68}$ Excerto em CURA, António Alberto Vieira Cura. Direito Romano e História do Direito Português (Casos Práticos Resolvidos e Textos), 2. edição. Coimbra Editora, 2009, pp. 366 a 379.

${ }^{69}$ Ver em CURA, António Alberto Vieira Cura. Direito Romano e História do Direito Português. 2009, pp. 370 a 373.

${ }^{70}$ Segundo o uso moderno: usus modernos pandectarum.

CUNHA, Joaquim Silva. História das Instituições. Aulas Teóricas. Vol. II. 2. a ed.
} 


\section{$\Downarrow$}

disciplina comum $\rightarrow$ Direito Natural, Público, Universal e das Gentes

- estudo da História do Direito Pátrio ${ }^{72}$

- adoptado o método sintético-demonstrativo-compendiário ${ }^{73}$

E os professores ficavam obrigados à redacção de um compêndio elementar da disciplina ${ }^{74} .75$

\section{CONCLUSÕES}

Hoje, como ontem, a Universidade é um conceito evolutivo que, desde um primeiro ciclo com um ensino mais "by the book" mas um segundo e terceiro ciclos em que o ensino deve ser fundamentalmente a partir da investigação, envolve a educação de pessoas. Ora, a educação, quer aos seis anos de idade quer no ensino universitário, deve preparar-nos para o estar vivo, em todas as vertentes desse entendimento ${ }^{76}$.

Surgiu a remodelação do ensino superior resultante do chamado Processo de Bolonha. Com origem na Declaração da Sorbonne de 25 de Maio de 1998 e na Declaração de Bolonha, de 19 de Junho de 1999, subscrita pelos Ministros de 29 países europeus responsáveis pelo ensino superior. O objectivo central da Declaração de Bolonha é o estabelecimento até 2010 de um Espaço Europeu de Ensino Superior, coerente, compatível, competitivo e atractivo para os estudantes europeus e de países terceiros, um espaço que promova a coesão europeia através do conhecimento, da mobilidade e da empregabilidade dos diplomados, de modo a permitir um melhor desempenho da Europa no Mundo e assim contribuir para a concretização da Estratégia de Lisboa. Esta mudança veio dar lugar, na Universidade Portucalense Infante D. Henrique, à unidade curricular semestral de História do Direito para substituir a disciplina anual de História das Instituições.

$\mathrm{Na}$ actualidade, a Universidade de Coimbra foi considerada a $14 .^{a}$ mais procurada da Europa na

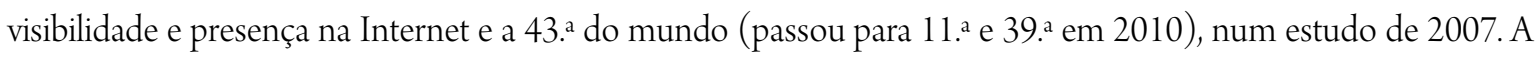
Universidade do Porto ficou em 54.o lugar na Europa (passou para 29.a em 2010) e 169.o no mundo ${ }^{77}$.

\footnotetext{
${ }^{71}$ Ver em CURA, António Alberto Vieira Cura. Direito Romano e História do Direito Português. 2009, p. 372.

${ }^{72}$ Relevo dado ao Direito Pátrio e ao estudo da História.

${ }^{73}$ Em todas as disciplinas, em substituição do método analítico que se mantém apenas para interpretação dos textos legais.

${ }^{74}$ O primeiro foi Historia Juris Civilis Lusitani, por Pascoal José de Melo Freire, em 1788.

${ }^{75}$ CUNHA, Joaquim Silva. História das Instituições. Aulas Teóricas. Vol. II. 2. ${ }^{\text {e ed., p. } 771 .}$

${ }^{76}$ Luís Fernandes em Uporto Alumini - Revista dos Antigos Estudantes da Universidade do Porto. N. 20 , II série, Agosto de 2014, pp. 6 e 7.

${ }^{77}$ Ranking elaborado pelo International Education Directory of Colleges and Universities (4ICU) para 9200 instituições de ensino superior em 200 países em todo o mundo mais consultadas na web. Jornal Público de 24 de Janeiro de 2009 e de 2 de Março de 2010.
} 
Merece ainda numa nota final mencionar que em $2014^{78}$ foi atribuída a Marca do Património Europeu (European Heritage Label) ${ }^{79}$, que destaca patrimónios que comemoram e simbolizam a integração europeia, os ideais e a história da União Europeia, à Biblioteca Geral da Universidade de Coimbra ${ }^{80}$, fundada há 500 anos, pelo seu pioneirismo: foi uma das primeiras bibliotecas na Europa a permitir o acesso público ao seu acervo e a organizá-lo em catálogos por temas para consulta. Em 2013, a Universidade de Coimbra, onde está incluída a biblioteca, fora classificada como Património da Humanidade pela Organização das Nações Unidas para a Educação, Ciência e Cultura (UNESCO).

\title{
THE PORTUGUESE UNIVERSITY: BEFORE AND TODAY - FROM ITS ORIGIN TO THE EIGHTEENTH CENTURY
}

\begin{abstract}
Yesterday and today, the University presents itself as a center of reflection and also center of attention of the public powers, yesterday, the king, today, the corresponding ministries and specialized commissions. The Portuguese University represents an institution, among its European counterparts, with specificities linked to the political evolution of the Kingdom, from its origin to the eighteenth century. It is appropriate to remember this specific origin, remaining the only institution of higher education of the country until the sixteenth century, at a time when the condition of the University and higher studies are again so spoken and studied.
\end{abstract}

Keywords: University, Law, Statute.

\section{REFERÊNCIAS BIBLIOGRÁFICAS}

ALMEIDA, Carlos Marques de. (1988). História das Instituições. Aulas Práticas. Vol. I e II. Porto: Universidade Portucalense, Centro de Cópias A. Silva Lemos.

ALMEIDA COSTA, Mário Júlio. (2005). História do Direito Português. Almedina, Coimbra. 3.a ed. (reimpressão).pp. 219 a 223, 229 a 232, 336 a 341, 371 a 377, 450 a 460.

ALVES, Manuel Valente. (2014). História da Medicina em Portugal. Porto Editora. ISBN 978-972-0-06292-5.

CURA, António Alberto Vieira Cura. (2009). Direito Romano e História do Direito Português (Casos Práticos Resolvidos e Textos), 2. a edição. Coimbra Editora. ISBN 978-972-32-1772-8

\footnotetext{
${ }^{78}$ Decisão da Comissão 2015/C 83/03 de 10 de março de 2015, que designa os 16 sítios aos quais é atribuída a Marca do Património Europeu em 2014, JOUE C 83 de 11.03.2015, p. 3.

${ }^{79}$ Decisão n. ${ }^{\circ} 1194 / 2011 /$ UE do Parlamento Europeu e do Conselho, de 16 de novembro de 201 1, JOUE L 303 de 22.11.2011, pp. 1 a 9.

${ }^{80}$ A Biblioteca Geral da Universidade de Coimbra em http://www.uc.pt/bguc.
} 
CRUZ, Guilherme Braga da (2008). O essencial sobre A História da Universidade. Imprensa Nacional-Casa da Moeda. ISBN 978-972-27-1655-0.

CUNHA, Joaquim Silva. (1987). História das Instituições. Aulas Teóricas. Vol. I e II. Porto: Universidade Portucalense, Centro de Cópias A. Silva Lemos.

(2003) Dicionário Houaiss da Língua Portuguesa. Lisboa: Temas e Debates.

MARQUES, Mário Reis. (2002). História do Direito Português Medieval e Moderno. Almedina, Coimbra. 2. ${ }^{\circ}$ ed.

(n. d.) POLIS. Enciclopédia Verbo da Sociedade e do Estado. Verbo.

SERRÃO, Joaquim Veríssimo. (1982). História de Portugal (1750-1807). Verbo. (1983). História das Universidades. Lello \& Irmão Editores, Porto.

SERRÃO, Joel. (1985). Dicionário de História de Portugal. Livraria Figueirinhas. Vol. VI, p. 228.

SOARES, Fernando José Gautier Luso. (2009). Ensaio para a História da formação do direito medieval português (O elemento romano). Prefácio. ISBN 978-989-652-020-5.

(2014) UPORTO ALUMINI - Revista dos Antigos Estudantes da Universidade do Porto. Entrevista a Luís Fernandes. N. ${ }^{20}$, II série, Agosto, pp. 6 e 7.

Trabalho enviado em 05 de julho de 2018.

Aceito em 24 de julho de 2018. 